
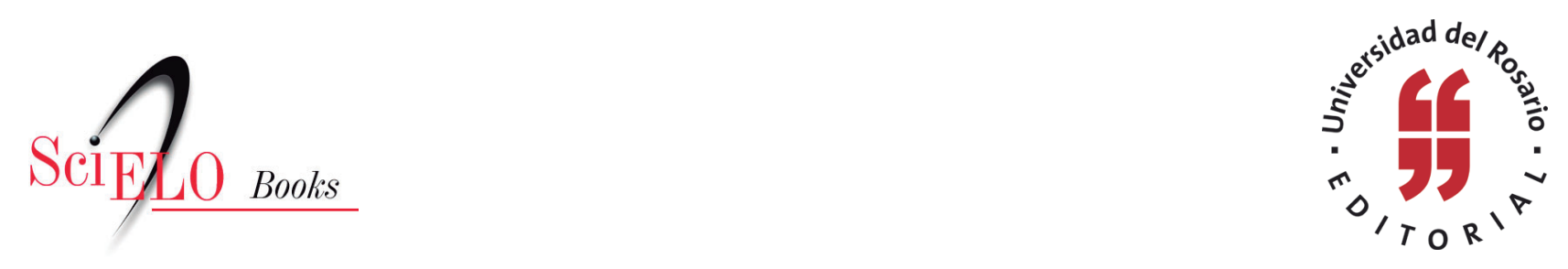

\title{
Narrativas sobre construcciones de subjetividad y autorreconocimiento indígena del pueblo nasa. Un pueblo de ancestros, luchas y reivindicaciones Avance epistemológico y conceptual
}

\author{
Naidú Liney Sastoque Espitia
}

\section{SciELO Books / SciELO Livros / SciELO Libros}

SASTOQUE ESPITIA, N.L. Narrativas sobre construcciones de subjetividad y autorreconocimiento indígena del pueblo nasa. Un pueblo de ancestros, luchas y reivindicaciones Avance epistemológico y conceptual. In: TORRES VILLARREAL, M.L., and IREGUI PARRA, P.M., ed. Discusiones contemporáneas sobre derechos humanos en el marco de la globalización [online]. Bogotá: Editorial Universidad del Rosario, 2015, pp. 1-33. ISBN: 978-958-738-671-4. https://doi.org/10.7476/9789587386714.0002.

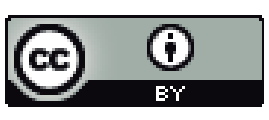

All the contents of this work, except where otherwise noted, is licensed under a Creative Commons Attribution 4.0 International license.

Todo o conteúdo deste trabalho, exceto quando houver ressalva, é publicado sob a licença Creative Commons Atribição 4.0.

Todo el contenido de esta obra, excepto donde se indique lo contrario, está bajo licencia de la licencia Creative Commons Reconocimento 4.0. 


\section{Narrativas sobre construcciones de subjetividad y autorreconocimiento indígena del pueblo nasa Un pueblo de ancestros, luchas y reivindicaciones Avance epistemológico y conceptual}

Naidú Liney Sastoque Espitia*

En este escrito se expone un avance en materia epistemológica y conceptual sobre el producto de semillero investigativo y la pasantía de investigación del proyecto Concepciones construidas por comunidades étnicas colombianas sobre la reparación integral como victimas del conflicto. Esto se soporta en el deseo de visibilizar, legitimar y tensionar las narrativas sobre subjetividad y autorreconocimiento del pueblo indígena colombiano nasa-paez, a través del análisis de los relatos de los actores del pueblo, contemplados desde un marco nacional de derechos

* Estudiante de X semestre de Psicología de la Fundación Universitaria Los Libertadores, semillerista de "Derechos Humanos y Minorías: Debates y retos en su implementación y eficacia de la Facultad de Derecho, Ciencias Políticas y Relaciones Internacionales”. Correo electrónico: nalisaes06@gmail.com 
humanos considerado como crítico, una historia imperante de violencia sociopolítica y una continua desacreditación de la indigenidad sobre los cánones de la vida occidental. De esta forma se rescatarán las narraciones sobre territorio, pertenencia y experiencia personal de ser indígena, propias de la construcción de subjetividades.

El proyecto está guiado bajo la directriz del socio-construccionismo y la psicología popular, con especial énfasis en los criterios de narración inteligible de Gergen y los rasgos de la narrativa de Jerome Bruner, para que mediante el dispositivo de las narrativas se esbocen los particulares matices de indigenismo de los nasas, se recreen escenarios de diálogo intercultural y se resignifiquen modos de acercamiento a las comunidades étnicas. Esto contribuye al conocimiento y a la visibilización del pueblo primigenio, sus procesos por autodefinirse y subjetivarse políticamente, especialmente en el escenario de la reparación. Asimismo, se busca invitar al debate a disciplinas afines con el fenómeno, garantizando la permanencia física y cultural de los pueblos y comunidades indígenas, a través de la divulgación de resultados y la invitación a discutirlos.

\section{Introducción}

En el momento neurálgico sociohistórico y político por el que atraviesa la Colombia del año 2015, con la negociación de paz con las farc (Fuerzas Armadas Revolucionarias de Colombia) — el acercamiento más significativo de las últimas décadas - resaltando las repercusiones en los procesos de significación y subjetivación que han tenido las nociones de violencia y guerra en la población colombiana durante poco más de medio siglo, y teniendo en cuenta que la situación de derechos humanos de nuestro país ha sido catalogada por la CIDH (Comisión Interamericana de Derechos Humanos) 
como "una de las más difíciles y graves de las Américas", se esboza un panorama de violación continua de derechos humanos en Colombia, especialmente para las comunidades y pueblos indígenas, donde todos y cada uno de los pueblos, según la onic (Organización Nacional Indígena de Colombia) están en riesgo de extinción física y cultural, debido a los efectos del conflicto armado interno, el modelo de desarrollo económico, la pobreza, la discriminación y el abandono institucional.

Con el reloj corriendo en contra de los colombianos cobijados bajo la Ley de Víctimas y Restitución de Tierras o Ley 1448 del 2011, que dicta las medidas de atención, asistencia y reparación integral a las víctimas, con la premisa de saldar una deuda moral con las víctimas, respaldado ello por el decreto-ley 4633 del 2011 — que dicta las medidas de asistencia, atención, reparación integral y de restitución de derechos territoriales a las víctimas pertenecientes a los pueblos y comunidades indígenas-, se hace visible un campo donde se hace estrictamente necesario el aporte disciplinar y profesional desde el marco de la psicología, para legitimar las voces de comunidades invisibilizadas, como los pueblos indígenas, en especial el pueblo nasa. Es allí donde nace el interés por estudiar el fenómeno de la subjetividad indígena de este pueblo primigenio, desde la categoría de las narrativas, con la finalidad de acercarse, en términos pragmáticos, a entender la diversidad étnica, la reconciliación, e invitar al debate a disciplinas afines con el fenómeno, como el derecho y la sociología, con el objetivo de co-construir el conocimiento y hacer un aporte a la acción psicosocial.

Lo hasta aquí señalado se basa en la situación actual del pueblo nasa, que ha sido continuamente relegado a ser una minoría, a ser invisible ante los ojos de los ciudadanos, y ello ha conllevado en muchos casos el olvido estatal y el prejuicio 
de una sociedad mayoritaria que naturaliza el desprestigio y el genocidio hacia lo indígena, que rechaza las actividades de su guardia indígena e impone sus estereotipos sociales sobre identidad y "maneras dignas de vivir" ante el fenómeno de subjetivación indígena de las nuevas y antiguas generaciones.

El pueblo nasa resistió por más de 150 años la fuerza destructiva de los conquistadores, en una guerra sangrienta en la cual la fuerza nasa buscaba evitar el exterminio de su pueblo. Para tal fin, se unificaron los cacicazgos en Tierradentro (Cauca), donde sobresalieron figuras como la cacica Gaitana y Juan Tama. Hacia 1650, la comunidad paez tuvo que aceptar algunos de los elementos culturales y el sistema que impuso la colonia para relacionarse con los 'blancos', razón por la cual tuvo de desaparecer la figura de los caciques y darle paso a los cabildos.

Dentro del horror que describen autores como Torodov en La Conquista de América, el problema del otro, hay una lucha y resistencia del pueblo paez, pueblo que además del atroz proceso de colonización, ha tenido que padecer los flagelos de medio siglo de conflicto armado colombiano, donde se han perpetuado y adaptado algunas de sus figuras, símbolos y prácticas. A título de ejemplo, el ser nasa se circunscribe dentro de un matiz de indigenismo particular, sin embargo, el prepararse y ser ratificado por la comunidad como kiwe thëgu (el que mira la tierra), es decir, un protector de la autonomía de la comunidad, dispuesto a defender la autoridad territorial, a proteger la tierra y contribuir a la preservación de la armonía y la unidad, tiene que ver con la conciencia de tener sentido propio, acorde a su identidad cultural, a la labor de alguacil o guardia indígena.

Como afirma la Cartilla del Resguardo Indígena Kwet Wala Dxüus Yat Nasa (Piedra Grande Casa Sagrada de los 
Nasa), "esta nueva estructura es de origen propio, soportada sobre nuestra propia Ley de Origen y nuestros principios, hace parte de nuestra búsqueda por autodefinirnos, y re-significar las funciones de nuestra comunidad desde nuestra propia identidad y cultura”. Es de esta forma que desde su lenguajear, sentir y actuar indígena, han transformado sus nociones y prácticas ancestrales para garantizar su pervivencia.

\section{El pueblo nasa-paez}

A continuación una breve contextualización sobre el pueblo nasa-paez o paez. Este es uno entre las variables cifras que datan el total de los pueblos indígenas colombianos, pues según la ONIC existen 102 pueblos, mientras que en los registros del DANe (Departamento Administrativo Nacional de Estadística), censo general del 2005, se encuentran 87 pueblos, con un número aproximado de 1'378 884 personas indígenas, 933800 asentadas en 710 resguardos existentes. En la disparidad de cifras se ven implicadas diferentes instituciones como la Dirección de Etnias del Ministerio del Interior y Justicia, el DNP (Departamento Nacional de Planeación), el Ministerio de Defensa y el DANE, lo que evidencia el desacuerdo nacional sobre el número total de pueblos, comunidades y personas que honran la diversidad étnica del país.

\section{Localización, demografía e historia}

Los nasas habitan a lo largo del sur de Colombia, en el departamento del Cauca se encuentra su territorio ancestral; sin embargo, hacen presencia en otros departamentos como Huila, Tolima, Meta, Putumayo, Caquetá y Valle del Cauca. Su población se estima en 360000 personas y se le considera el segundo pueblo indígena más numeroso de Colombia. De su historia se puede referir que el pueblo nasa creó sus resguardos 
indígenas a mediados del siglo xviıI, y en el siglo xx Quintín Lame lideró el movimiento indígena y consolidó el cabildo como autoridad. Este pueblo ha sido emblemático en materia de lucha y resistencia: asediado tras la fundación de Popayán, evangelizado por jesuitas y franciscanos, despojado de sus tierras por ganaderos, azotado por la violencia sociopolítica y los intereses particulares de organizaciones mineras, entre otros graves hechos.

\section{Mecanismos de autoabastecimiento}

Los paéces, o integrantes la comunidad nasa-paez, son un pueblo agrícola que se autoabastece, pues dentro de su mentalidad el ser nasa-paez implica ser un buen trabajador de la tierra. Uno de los ejes centrales en su cultivo es el maíz, tanto así que se habla de la "cultura del maíz". Su forma de trabajo representativa es el trabajo colectivo o minga, que permite que cada individuo aporte a la comunidad (Observatorio de Derechos Humanos y Derecho Internacional Humanitario [Observatorio de DDHн у DIH], 2010).

En esta línea de conservación de prácticas tradicionales, los nasas realizan labores artesanales, donde fabrican mochilas para uso cotidiano o venta; también elaboran una especie de cargador para los niños, denominado chumbe, y pequeñas mantas y cobijas de oveja; en ocasiones, también tejen sombreros de caña brava. Finalmente, la economía de este pueblo se basa en la agricultura (cultivo de maíz y laurel, que a su vez se utilizan en la medicina tradicional), la posesión y el cuidado de rebaños de ovejas, labor esta última que desempeñan las mujeres.

La fuente económica de las familias paeces es de base agrícola, la cual se combina con prácticas pecuarias, aunque en menor escala. Dentro de los productos que producen se encuentran: maíz, arracacha, yuca, plátano, fríjol cacha (silvestre), 
papa, habas, repollo, ullucos, cebolla, cilantro, chachafruto, caña de azúcar, pastos, ganado vacuno, porcino, ovino, caballar, pato, aves de corral, conejos, la mayoría de los cuales se orientan al autoconsumo. La base de la alimentación es el maíz (Pito, 2001).

\section{Lengua nativa o propia: nasa yuwe}

Los nasas poseen una lengua particular llamada nasa yuwe. Según el DNP (2010), 42,1\% del pueblo nasa-paez conserva su lengua, es decir, 78064 personas aún la hablan. Asimismo, "El páez o nasa yuwe (dicho en su idioma) aparece en varias clasificaciones como perteneciente a la familia chibcha, pero esta clasificación ha sido rechazada (Constenla, 1993). Por esta razón el paez con sus variantes, aparece como lengua aislada” (Sistema Información Indígena de Colombia [sıIc], 2009).

\section{Formas organizativas sociales y políticas}

A nivel político y organizativo, la figura principal del pueblo nasa es la Asociación de Cabildos del Norte del Cauca (ACIN), que a su vez hace parte del Consejo Regional Indígena del Cauca (CRIC) y de la Organización Nacional Indígena de Colombia (onic). La Acin o ACin cXab wala kiwe (Territorio del Gran Pueblo) nació en 1994 en Santander de Quilichao, con la intención de conformar una comunidad político-territorial y constituirse como territorio autónomo indígena, fortaleciendo al mismo tiempo las relaciones interétnicas, la armonía con la Madre Tierra y la participación política, económica y administrativa de la comunidad. Con estas pretensiones lograron agrupar diecinueve Cabildos y catorce resguardos indígenas de ocho municipios (Toribío, Caloto, Miranda, Corinto, Jambaló, Santander de Quilichao Buenos Aires y Suárez). 


\section{Cosmovisión}

La cosmología nasa tiene como elemento fundamental la casa yet, un espacio de construcción colectiva de la vida, metáfora construida a partir de su ley de origen, luego del llamado de los abuelos a los a los espíritus y vientos, invitándolos a cesar el daño; de esta forma los abuelos son los integradores del todo y los espíritus adquirieron cuerpo. Para estas comunidades así es el universo y de esta manera surgen las casas tanto de los animales como la casa de los nasas. Estas casas tienen corazón (fogón), ojos (ventanas), boca (puerta), costillas (paredes) y piernas (columnas). Está tan cimentada la idea primigenia sobre la casa como espacio de abrigo, que los principales héroes culturales se han destacado por defender su casa y su territorio, como Dxi'pam, el rostro del trueno.

Para el pueblo nasa, existen principios básicos por los que se orienta la vida, al cumplirlos se logra el estado final esperado: la armonía. El primero de estos principios es la espiritualidad (vivida a través de la relación con todos los seres, espíritus, fuerzas naturales y la comunidad presente en su territorio). El segundo está dirigido al uso respetuoso de la Madre Tierra, fuente de energía y vida, pues el territorio es la casa de abrigo, y por lo tanto se debe aplicar el "Tül”, un sistema tradicional de producción aborigen. Finalmente, la reciprocidad entre la comunidad, la tierra y la naturaleza debe fomentarse desde el trabajo comunitario (mingas), que establece el derecho a dar y recibir equitativamente sin causar daño o mal a otros, distribuyendo colectivamente los recursos, las oportunidades y la producción.

Dentro de los ámbitos ancestrales e intergeneracionales, una de las plantas más utilizadas por el pueblo nasa es la coca, la cual es vista como sagrada (Observatorio de DDHH y DIH, 2010). Pito (2001) sostiene que la medicina tradicional es 
celosamente conservada por los mayores, pues con el saber milenario el médico protege la vida de aquellas enfermedades culturales (el chamán establece que son provocadas por un duende de parcela, arcoíris, otro chamán, un desequilibrio espiritual, alteración de espacios sagrados por mujer menstruante, etc.) y naturales (producidas por accidentes, epidemias, parásitos, etc.). De igual forma, este personaje se encarga de limpiar los espacios para construir una vivienda, realizar limpiezas, "voltear" el mal a quien se vea afectado o ahuyentarlo.

En términos generales, los paeces han visto vulnerado su derecho a una integridad cultural y una identidad étnicacultural, porque las múltiples intrusiones de diferentes actores han ido en contravía de sus costumbres, acabando incluso con la transmisión generacional del nasa yuwe en los niños y jóvenes; por otro lado, dichos actores han privado a este grupo indígena del goce de un ambiente sano y ecológico. Es el caso de las empresas interesadas en la minería y los agrocombustibles, pues acaban con sus fuentes hídricas y van en detrimento del medio ambiente de la región.

Algunas instituciones estatales y empresarios han negado el derecho de los nasas al territorio, causando hacinamiento en los municipios donde se concentra este pueblo. Además, los grupos traficantes de drogas han establecido cultivos de coca, así como laboratorios y rutas para la cocaína, lo cual ha impactado al mismo tiempo las costumbres nativas, la concepción sobre el trabajo y las prácticas ancestrales de las nuevas generaciones, llegándose incluso a persuadir a los jóvenes para laborar en el ilícito.

La situación de conflicto armado no solo ha acabado con la vida de figuras fundamentales de la vida en comunidad, tales como profesores, líderes y guardias indígenas, sino que ha hecho cundir la sensación de inseguridad y que se viole la 
libre movilización por el territorio, con lo cual se ha afectado la vida digna, la autonomía política y organizativa, la seguridad alimentaria y el desplazamiento, con acciones como la siembra de minas antipersona, carros-bomba, enfrentamientos aéreos, etc. Estos hechos han sido divulgados por algunos medios de comunicación como la "muerte accidental de dos indígenas Nasa" o amenazas a veintiséis líderes de la comunidad perpetrada por actores armados de las FARC.

Aún quedan muchos otros hechos por esclarecer, como los ocurridos en abril del 2001 cuando un numeroso grupo de paramilitares del Bloque Calima amedrentó y asesinó a decenas de indígenas y afrodescendientes en la hacienda E1 Naya, hechos en los que la Unidad de Justicia y Paz estableció veinticinco víctimas mortales, mientras que la comunidad habla de aproximadamente cien personas fallecidas, muchas de ellos arrojadas al río Naya o lanzadas por abismos. ${ }^{2}$

Los nasas han sido insistentes en su exigencia al Gobierno nacional, organismos de control internacionales y ante los mismos actores armados al margen de la ley, de cesar los operativos militares en su región, recordando que los cubre el derecho internacional humanitario y reclamando a su vez el derecho a la autodeterminación como pueblo indígena,"a caminar sin temor de minas antipersonales, munición sin explotar, bombardeos aéreos o enfrentamientos":

1 Mayor información en http://www.eltiempo.com/politica/justicia/farc-diceque-muerte-de-indigenas-fue-un-error/14822437 y http://www.bluradio.com/81949/ milicianos-que-mataron-lideres-indigenas-en-cauca-fueron-presionados-farc

2 Mayor información en http://www.verdadabierta.com/lucha-por-latierra/5264-la-sangre-que-les-recupero-la-tierra-de-los-nasa 
No solamente sufrimos las consecuencias de la guerra, sino que se nos victimiza y además se nos señala y estigmatiza por los gobiernos nacional y departamental, y también, por las cúpulas y altos mandos militares. Esta situación nos coloca en alto riesgo y cuando se da una confrontación armada entre los actores del conflicto, nos vemos obligados a abandonar nuestras parcelas y cultivos y a pasar largos períodos sin alimentos. (Observatorio ADPI, s.f.)

He aquí una de las descripciones superficiales que relatan lo que sucede con las categorías que son materia de interés y estudio de este proyecto: el autorreconocimiento y la subjetividad indígena. Esta primera noción se encuentra directamente relacionada con la labor del psicólogo en contexto jurídico, pues pretende utilizar el saber disciplinar para, de y en el campo del derecho. Asimismo, se relaciona con categorías psicológicas, sociales y sociológicas como identidad y pertenencia, territorio, ancestralidad, victimización y vulnerabilidad.

\section{Subjetividad y autorreconocimiento}

El autorreconocimiento comprende la construcción de subjetividad y el entretejido de intersubjetividades, así como los procesos de empoderamiento en lucha y el mecanismo de resistencia de los pueblos. Como afirman Díaz y González (2005), la subjetividad está mucho más allá de ser una "no objetividad", somos sujetos en proceso, no se trata de influencias que de forma inmediata, directa, unilineal, hayan configurado nuestra subjetividad, sino de "recortes, consecuencias y episodios aislados de esas experiencias las que, a través de la forma en que las vivimos, definen nuestra organización" (p.6).

Los citados autores plantean una subjetividad anclada en una perspectiva histórico-social abanderada por autores como 
Vygotsky, idea que mantiene la línea de coherencia interna y establece un punto de cohesión con los otros autores a los que acudimos con la categoría narrativa, es decir, Bruner y Gergen. Para Díaz y González (2005) existen múltiples conceptos que intervienen en la discusión como lo son subjetividad social, subjetivación, subjetividad individual y subjetividad política, entre otros. A continuación un breve recuento sobre las nociones trabajadas por estos psicólogos, colombiano y cubano, (Díaz y González, 2005): en primer lugar, "la subjetividad se forma socialmente, pero no es la 'suma objetiva' de lo vivido: representa una producción arbitraria y distorsionada de la experiencia que se produce a partir de un momento real o imaginario en que un espacio de esa experiencia se carga de emocionalidad y se desdobla en múltiples alternativas simbólicas"(p. 11).

Desde la perspectiva del renombrado psicólogo cubano Fernando González Rey, hay una complejidad que debe reconocerse desde la psicología, complejidad que a manera de símil acaba por ser un molde constituido socialmente: "el hombre se produce sobre/ desde/ dentro de lo social [...] La subjetivad social no es una antropomorfización de lo social es el proceso subjetivo cargado de sentidos y procesos simbólicos que se desdoblan entre un conjunto de figuras sociales $[. .$.$] creo la$ subjetivación es el proceso mediante el cual permanentemente se da esa integración simultánea entre los espacios individual y social" (p.9).

\section{Algunas consideraciones sobre el proyecto}

Así como se viene dilucidando esta multiplicidad de procesos relativos a la subjetividad que ocurren alrededor de lo social, individual, emocional y psíquico, de igual forma, la autora de este proyecto considera que posiblemente el proceso de reparación 
integral dentro del que está enmarcado el proyecto de investigación Concepciones construidas por comunidades étnicas colombianas sobre la reparación integral como víctimas del conflicto, en su primera fase, de consulta previa y concordancia con el enfoque diferencial, puede potenciar o ir en detrimento de la construcción y reivindicación de la subjetividad diferencial. Finalmente, en la segunda fase se pretende analizar las narraciones sobre dichas categorías, para develar descripciones densas que hermenéuticamente intentan trabajar sobre el sentido y el significado de lo que se narra, porque como sostienen Díaz y González (2005):

[...] la subjetividad política es un momento de una subjetividad social [...] Porque cuando hablamos de subjetividad política, en ella, está la religión, están las creencias, están los mitos [...] están una cantidad de cosas que en sentido estricto no forman parte de la actividad de la organización política. Esa subjetividad política son síntesis de una subjetividad social con desdoblamientos infinitos, de allí que me cuesta trabajo seccionar la subjetividad, decir que esto es dominio de la subjetividad política. (p. 13)

\section{Reparación: un concepto que transita entre la psicología y el derecho}

El lector se preguntará el porqué del título de este aparte, pues el concepto reparación, en el que trasciende la acción psicosocial del presente proyecto, está cimentado en la noción simbólica, de la que se ocupa la psicología. Esto se expone ampliamente a continuación.

La reparación simbólica, concepto trabajado por Guilis (2005), parte de utilizar los conceptos del derecho para la práctica psicojurídica, entendiendo el reto que supone tal propósito en materia de significados y visiones epistémicas y sus 
incidencias en la subjetividad. La reparación no debe ser vista como la imposición de una cuota de dolor que corresponda al dolor causado, antes bien debe apuntar a producir subjetivamente en la víctima el desmantelamiento de las condiciones que produjeron el trauma/dolor. El concepto entonces no debe estar direccionado solo por las nociones de lo justo, sino también por las de bien o bueno.

Según la onu (citada por Guilis, 2005), las víctimas, en todos los niveles, tienen el derecho a ser reparadas por todos los daños y perjuicios producidos. Este derecho se despliega en: restitución (retorno a la situación antes del daño), indemnización (cubriendo los daños psíquicos, físicos, morales, pérdida de oportunidades, entre otros) y rehabilitación (tipo médico, psicológico, psiquiátrico o activación de redes). En este orden de ideas, la autora reconoce que los propósitos que se plantean, en especial la recuperación de la situación previa al daño, presentan un posible simbólico, tras la imposibilidad material. En este lugar de lo simbólico, donde tiene cabida la reparación, es imprescindible involucrar la subjetividad del afectado y su connotación sobre el concepto de reparación.

Ahondando en el ámbito simbólico, es necesario remitirse a la genealogía psicológica de la reparación. En este sentido, Guilis (2005) reconoce a Melanie Klein como la pionera en utilizar el término en la disciplina, aludiendo a un mecanismo intrapsíquico, mientras que para la visión jurídica obedece al plano de lo externo. El carácter simbólico se matiza en dos puntos neurálgicos: el primero de ellos hace referencia a que la reparación es simbólica, siempre que sea una representación (cualitativa o cuantitativa) de aquello que se ha perdido o flagelado, y nunca lo dañado en sí mismo, pues se persigue un imposible cuando la pretensión es resarcir la totalidad de 
los perjuicios, por lo cual se aproxima en mayor medida al acto de justicia que al de restitución.

En segunda instancia, la reparación se hace simbólica en la medida que está completamente expuesta al proceso de significación que la víctima le otorgue a lo perdido y lo ofrecido por la reparación, abriéndose con ello el panorama a un proceso único, íntimo y singular en el trabajo de simbolización: "el símbolo (reparación) no mantiene con lo simbolizado (aquello que se ha perdido y cuya pérdida debe repararse) una relación unívoca y fija" (Guilis, 2005, p. 97); por el contrario, el sujeto afectado está continuamente modelando el símbolo, y lo que este representa no será una cosa, sino la recomposición que el psiquismo logra hacer de lo perjudicado.

En esta visión, es necesario distinguir entre el acto reparatorio y la reparación. El primero se lleva a cabo en el proceso de justicia, donde el que ha dañado está obligado a reparar; sin embargo, los efectos reparatorios corresponden al orden psíquico de la víctima, lo que reivindica su autonomía psicológica, evitándose la idea de que el gesto que pretende reparar, en realidad produce tal efecto y hay otro pretendiendo dominar o someter su psiquismo a un efecto particular.

La reparación implica pensar en qué se puede reparar, tras definir claramente qué fue lo perjudicado. En este sentido, se distinguen el daño moral y el daño psíquico, el que se inflige al sujeto jurídico (corte universalizante) y el que tiene en cuenta la dimensión subjetiva que afecta el uso de las potencialidades y recursos (corte singular). Esto hace que el daño moral sea cercano a la indemnización y que el daño psíquico requiera otros esfuerzos, pues reconoce la concepción del acto reparatorio por parte de la víctima, sin olvidar que en la justicia debe apaciguarse su dolor, pues "el acto de justicia, la definición de las responsabilidades y la aplicación de la pena correspondiente, 
son en sí mismos actos reparatorios"(Guilis, 2005, p. 112). Dichos actos no pretenden retornar a un estado, sino devolver la característica de espacio habitable a la vida social de la víctima.

Por otra parte, las leyes de reparación económica en materia de indemnización incluyen el reconocimiento del hecho por parte del Estado, la verdad de los hechos y la aplicación de la pena correspondiente. Finalmente, Guilis (2005) dilucida cómo hay un concepto de compleja definición y difícil consenso que intermedia todo lo hasta aquí dicho: el de dignidad.

América Latina es considerada uno de los espacios geográficos en donde se han acentuado en mayor medida los procesos de desaparición forzada, los cuales, lamentablemente, se vieron sustentados por un marco político e ideológico. En Colombia hubo el atenuante de que las más altas cifras de desaparición forzada se registraron durante gobiernos elegidos democráticamente, mientras que en países como Chile este fenómeno se dio en la búsqueda del restablecimiento de la democracia. En este contexto, emerge la imperiosa necesidad de la intervención psicosocial del profesional en psicología, ahondando en los aspectos éticos, teóricos y procedimentales, y por lo tanto se requiere revisar la noción de trauma (Bravo, 2011).

Bravo se basa en el aspecto eminentemente psicosocial del trauma, distinguido por Martín Baró (retomado por Bravo, 2011) y su elemento dialéctico, en donde el sujeto está vinculado a un sistema de relaciones que ha de ser tenido en cuenta para la superación, evitándose con ello mantener las condiciones sociales que produjeron el hecho.

Bravo (2011) cita a González, teniendo en cuenta su particular perspectiva en el reconocimiento del sentido subjetivo dado por la unidad de los procesos simbólicos y emocionales, que en este caso no contribuyen al procesamiento adaptativo de lo sucedido. El autor llega a la conclusión de que la reparación 
integral debe esclarecer tanto la forma de producción del hecho, la escala de responsabilidades y el reconocimiento de las víctimas como actores activos del proceso, con voz propia y en capacidad de empoderarse nuevamente de sus derechos.

\section{Metodología}

Se pretende identificar las narrativas de daño, violencia, vulnerabilidad, conflicto, identidad, indigenismo y territorio que esbozan la narrativa de subjetividad de los actores del pueblo indígena nasa, por medio del análisis sistemático de la recolección de relatos realizada por los profesionales, técnicos y enlaces étnicos de la Unidad de Atención y Reparación Integral a Víctimas (UARIV), entidad que apoya el proyecto de investigación Reparación integral con comunidades y pueblos indigenas de Colombia: retos y perspectivas en escenarios de construcción de paz.

Posteriormente, se pretende codificar la información por medio de una matriz de integración, a través de unidades de análisis o categorías, como productos de la integración con la información encontrada en la investigación y con los fundamentos teóricos, en este caso los criterios de narración inteligible de Gergen y los rasgos de la narrativa de Jerome Bruner. Por último, se condensan como etiquetas categoriales elaboradas y complejas, entretejidas con la cosmovisión del pueblo y la comunidad indígena a la que se alude.

Desde la postura hermenéutica adoptada por la psicología popular de Bruner, se intentará lo que los investigadores cualitativos han denominado un proceso de "artesanía intelectual”, que dilucide las descripciones de cada categoría encontrada en los metarrelatos sobre reparación y las relaciones entre categorías. Estas últimas deben contribuir a una aproximación sobre las prácticas, cosmovisiones y expectativas 
de las comunidades indígenas sobre la reparación en un marco de reparación integral, y asimismo, desde la disciplina psicológica, a la permanencia física y cultural de los pueblos y comunidades indígenas, a través de la divulgación de resultados y la invitación a su discusión.

\section{Resultados parciales}

A continuación se expondrán los marcos de referencia tenidos en cuenta para la consolidación de la primera fase del proyecto de pasantía de investigación, la cual básicamente afianza la visión epistemológica, conceptual y categorial del proyecto.

\section{Marcos de referencia}

Estos son el marco jurídico y el marco disciplinar.

\section{Marco jurídico}

En primer lugar, la Ley 89 de 1890, "Por la cual se determina la manera como deben ser gobernados los salvajes que vayan reduciéndose a la vida civilizada", regulaba los cabildos y resguardos indígenas. Luego, con el advenimiento del Convenio 169 de la oit (Organización Internacional del Trabajo) en 1989, Colombia asumió la responsabilidad de desarrollar una acción coordinada y sistemática para proteger el derecho de los pueblos y garantizar el respeto a su integridad. Este convenio fue ratificado por la Ley 21 de 1991,y ese mismo año la nueva Constitución Política introdujo artículos que destacan el carácter pluriétnico de la nación; entre estos se destacan:

- "El Estado colombiano reconoce y protege la diversidad étnica y cultural de la Nación Colombiana"(Art.7).

- “... las lenguas y dialectos de los grupos étnicos son también oficiales en sus territorios. La enseñanza 
que se imparte en las comunidades con tradiciones lingüísticas propias, será bilingüe”(Art. 10).

- “... todas las personas gozan de derechos, libertades y oportunidades sin ninguna discriminación por razones de sexo, raza, origen, lengua, religión"(Art.13).

- "Las tierras de resguardo [...] son inalienables, imprescriptibles e inembargables" (Art. 63).

- “... tendrán derecho a una formación que respete y desarrolle su identidad cultural..."(Art. 68).

- Circunscripción especial para asegurar la participación de los grupos étnicos en el Senado y en la Cámara de Representantes (Arts. 171 y 176).

- Las autoridades de los pueblos indígenas podrán ejercer funciones jurisdiccionales dentro de su ámbito territorial, de conformidad con sus normas y procedimientos, siempre que no sean contrarios a la Constitución y a las leyes (Art. 246).

- "Son entidades territoriales los departamentos, los distritos, los municipios y los territorios indígenas" (Art. 286).

- La conformación de las entidades territoriales indígenas se hará con sujeción a lo dispuesto en la ley orgánica de ordenamiento territorial [...] los resguardos son de propiedad colectiva y no enajenable"(Art.329).

- “... los territorios indígenas estarán gobernados por consejos conformados y reglamentados según los usos y costumbres de sus comunidades y ejercen entre otras funciones la de velar por la preservación de los recursos naturales..."(Art. 330).

Según la página web de la Universidad del Rosario (s.f.), posteriormente, la Ley 60 de 1993 dictaminó que los resguardos 
indígenas habían de beneficiarse de los recursos presupuestales del país, mediante transferencias proporcionales a su número poblacional. De otra parte, con el Decreto 1088 de 1993 se reguló la creación de las asociaciones y cabildos indígenas.

La Ley 152 de 1994, por su parte, estableció la acción administrativa y coordinada de los departamentos, entes territoriales, regiones administrativas y de planeación, así como un sistema de información para elaborar diagnósticos y realizar labores de seguimiento, evaluación y control de los planes de desarrollo por parte de las entidades territoriales y de planeación. El Decreto 2164 de 1995 reglamentó parcialmente el capítulo Xiv de la Ley 160 de 1994 en lo relacionado con la dotación y titulación de tierras a las comunidades indígenas para la constitución, reestructuración, ampliación y saneamiento de los resguardos indígenas en el territorio nacional. En 1996 se expidió el Decreto 1397, por el cual se creó la Mesa Permanente de Concertación con los pueblos y organizaciones indígenas y se dictaron otras disposiciones.

En el 2009, la Corte Constitucional colombiana dictó el auto 004, para la protección de los derechos fundamentales de las personas y los pueblos indígenas desplazados por el conflicto armado o en riesgo de desplazamiento forzado, y un año después el 382 del 2010, que declaró que existían 35 pueblos indígenas en riesgo de extinción física y cultural.

En el año 2011 se promulgó la Ley 1448, de Víctimas y Restitución de Tierras, una iniciativa gubernamental para la prosperidad en materia de seguridad, empleo, superación de la pobreza y especialmente a fin de dictar las medidas para el restablecimiento de la confianza y un camino hacia la reconciliación mediante la reparación integral. De igual forma, dictó la política pública que creó el snariv (Sistema Nacional de Atención y Reparación Integral a Víctimas), el Centro de Memoria Histórica y 
el Departamento Administrativo de Inclusión Social y Reconciliación. Se estableció asimismo la noción de víctima (soportada a su vez por la Sentencia C-052 de 2012) individual y colectiva; se dictaron las medidas de reparación (restitución, indemnización, rehabilitación, satisfacción y garantías de no repetición) para cada tipo de víctima en sus diferentes dimensiones (individual, colectiva, material, moral y simbólica).

Los principios esenciales que orientan esta ley son, básicamente, los de: dignidad, buena fe, igualdad, justicia transicional, debido proceso, enfoque diferencial, progresividad, gradualidad, derecho a la verdad, justicia, reparación integral, colaboración armónica de las instituciones públicas y prevalencia de los tratados internacionales en materia de derechos de las víctimas.

Esta ley es secundada y pormenorizada por el DecretoLey 4633 del 9 de diciembre del 2011, "por medio del cual se dictan medidas de asistencia, atención, reparación integral y de restitución de derechos territoriales a las víctimas pertenecientes a los Pueblos y Comunidades indígenas", que a su vez, en sus primeros artículos establece el respeto al plan de vida oral o escrito, el ordenamiento ancestral, la cosmovisión y/o ley de origen, la ley natural, el derecho mayor o derecho propio, el derecho al acceso y protección del territorio, el reconocimiento y la visibilización de los daños y violaciones históricas, entre otros.

La norma en mención ha sido asimismo reglamentada por los decretos 4800, 4155, 4633 y 4635 del año 2001, que puntualizan campos específicos de la política establecida para la atención y la reparación de las víctimas de la violencia y el conflicto armado. De igual forma, el documento Conpes 3726 del 2012 fijó los lineamientos, el plan de ejecución de 
metas, el presupuesto y el mecanismo de seguimiento del Plan Nacional de Víctimas.

\section{Marco disciplinar}

\section{Narrativas}

La investigación acerca de narrativas del pueblo nasa sobre subjetividad y autorreconocimiento como persona-indígena, en el marco de la violencia sociopolítica colombiana y la reparación integral, se pretende realizar desde la perspectiva epistemológica del socio-construccionismo y una tradición teórica que acoge postulados de una psicología cultural centrada en la psicología popular de Bruner, la cual adopta lo narrativo como principio organizativo, pues comprendemos el mundo narrándonos la trama construida. Es necesario dilucidar que este eje categorial de narrativas ha sido ampliamente estudiado por autores como Theodore Sarbin, Britton y Pellegrini, Hyden White, Keneth Gergen y Jerome Bruner.

En este trabajo se tienen en cuenta las propuestas de Bruner y Gergen, quienes a pesar de converger desde perspectivas epistemológicos diferentes, concluyen que las exposiciones narrativas están incrustadas en la acción social, mostrando una gran sensibilidad en la base sociocultural y sus sistemas de significación, de manera que las narraciones del yo no son posesiones exclusivas del individuo, sino de las relaciones, pues son productos del intercambio social. Como retoma Bruner (1990) de Clyde Kluckhohn, los seres humanos no terminan en su propia piel, son expresión de la cultura.Además, “[...] la narración es un mecanismo fundamental de comprensión de sí mismos y de los otros, por lo que la relación entre la narrativa y la formación o transformación es una reflexión sobre la identidad" (Larrosa, 1998, p. 388). 
Para el estadounidense Gergen (2007), las narrativas hacen que los acontecimientos sean socialmente visibles y establezcan característicamente expectativas para acontecimientos futuros, es decir, se vuelven expresión política, en tanto también delimitan y provienen de la interacción con el otro. Por tal motivo, se adopta esta visión para examinar las narraciones (autonarraciones) como formas sociales de dar cuenta que funcionan como historias orales, que cumplen la función de autoidentificación, autojustificación, autocrítica y solidificación social, en el marco de la reparación integral. En esta línea, "la vida es un acontecimiento narrativo" (Gergen, 2007, p. 69), y a su vez la narración es un dispositivo para lograr que los acontecimientos sean inteligibles, para darle organización y sentido al mundo, pues como sostiene White, en muchos sentidos la palabra es el mundo.

Finalmente, al utilizar la categoría de narrativas, se hace indispensable revisar los criterios de una narración inteligible de Gergen y los rasgos de la narrativa de Bruner, entendiendo que - como afirma Sarbin - si la psicología es historia y se acepta que la historia es narración, se puede decir, con la brevedad y contundencia de una fórmula, que la psicología social es narración. El proponernos el uso de este eje conceptual supone al mismo tiempo retos metodológicos, epistemológicos y pragmáticos como investigadores, en tanto se han de reconocer las emociones como integrantes esenciales del metarrelato, condicionantes del parámetro de significación para los contenidos de la memoria y propias del estilo comunicativo de los actores indígenas. Además, movilizan sus creencias.

Para poder visibilizar los relatos es necesario ponerse en sintonía con su cuadro cosmogónico, para validar, legitimar y escuchar activamente, desde el entendimiento de otra manera particular de connotar la realidad, teniendo en cuenta 
un marco de referencia salido del esquema de la colonización del pensamiento occidental. Esto supone, además, poner en contexto las versiones que abren el espacio de la memoria incluyente y la visibilización de comunidades invisibilizadas, para finalmente convocar a los investigadores a la construcción de conocimiento desde el reconocimiento de las relaciones de poder, de la otredad como lugar válido para existir y narrar, que suponen el trabajo del psicólogo en un país marcado por una realidad sociopolítica impregnada de violencia.

La narración tiene la función de dotar de sentido al mundo, pues procede de sistemas de referencia estructurados, es decir, marcos interpretativos otorgados cultural y socialmente, en tanto que la narrativa como marco social de la memoria se consolida debido a que esta última conserva aquello que le es significativo, y esta significación obedece a una historia entretejida con la cultura y la historia de vida. Como señala Bruner (citado en Mendoza, 2004), "la experiencia y la memoria del mundo social están fuertemente estructuradas no sólo por concepciones profundamente internalizadas y narrativizadas de la psicología popular sino también por las instituciones históricamente enraizadas que una cultura elabora para apoyarlas e inculcarlas". De manera que lo que no se estructura de forma narrativa, se pierde en la memoria.

De igual forma, estos modelos narrativos se sustentan en la hermenéutica, pues de acuerdo con Bruner (citado en Mendoza, 2004), se intenta establecer una lectura del texto completo y para ello apelamos a lecturas de sus expresiones parciales, intentando dotar al todo de sentido.

Comunidades como las indígenas utilizan la oralidad como recurso narrativo para salvaguardar su historia, cosmogonías e identidad, contrarrestando el riesgo del olvido. Por esta razón, sus narrativas tienen tendencia a la repetición y se 
acoplan a un producto social de colonización y vulneración. Es por ello que autores como Eco (citado en Mendoza, 2004) sostienen que la "memoria colectiva se las arregla, a veces, para sobrevivir a las censuras del poder y a los silencios de la historia”.

Para Bruner (citado en Rojas, 2013), dentro de las dos modalidades de pensamiento, la pragmática y la narrativa, se producen argumentos y relatos respectivamente. En estos últimos, el eje central es la similitud en la vida, pues tienen la posibilidad de significar la experiencia. A su vez, el lenguaje es vehículo productor de significados y producido por relaciones. Según Bruner, el estudio apropiado del hombre está basado en la conexión indispensable con el mundo cultural, en tanto se hace necesario socavar las narraciones del mundo de la cultura para contribuir a la construcción del conocimiento.

Para el psicólogo social, el lenguaje y la cultura se asumen como interdependientes, como tejedores mancomunados en la construcción de herramientas que permiten la vida en comunidad, a través de la construcción de sistemas simbólicos que dan cuenta de "procesos de construcción y utilización de significados que conectan al hombre con la cultura [...] procesos de interpretación y negociación de significados compartidos" (Bruner, 1990, p. 28).

Con el paso del tiempo son tres las cuestiones que posibilitan la narrativa: a) la eficacia a distancia: hablar de objetos sin tenerlos físicamente; b) la arbitrariedad: los signos pueden no parecerse a lo referido; y c) la gramática de casos: cierta sintaxis. Así,"el sacerdote-actor ritual puede formular con sus palabras un buen augurio para la siembra, así como el cronista que relata un combate con las tribus vecinas o el padre que habla a su hijo de ancestros a imitar; y todo esto puede ser dicho, años más tarde, en cualquier sitio, junto al hogar, a una 
sola persona o a muchas, o inclusive a uno mismo" (Bruner, citado por Mendoza, 2004).

De acuerdo con Gergen (2007), los criterios que explicitamos a continuación parecen ser primordiales en la construcción de una narración inteligible para segmentos importantes de la cultura contemporánea. En primer lugar, el establecer un punto final apreciado, pues un relato aceptable tienen que delimitar una meta, un acontecimiento que explicar, un estado que alcanzar o evitar, un resultado de significación o, dicho más informalmente, un "punto". En segunda instancia, seleccionar los acontecimientos relevantes para el punto final, en tanto los tipos de acontecimientos que pueden aparecer en la exposición, reduciendo grandemente la mirada de candidatos a la "cualidad de acontecimiento". Un relato inteligible es aquel en el que los acontecimientos sirven para hacer que la meta sea más o menos probable, accesible, importante o vivida (Gergen, 2007).

De igual manera, se tienen en cuenta la ordenación de los acontecimientos y la estabilidad de la identidad, ya que la narración bien formada es característicamente aquella en la que los personajes (o los objetos) del relato poseen una identidad continua o coherente a través del tiempo. Por otra parte, las vinculaciones causales y signos de demarcación, teniendo en cuenta que la mayoría de relatos apropiadamente formados emplean señales para indicar el principio y el final.

Para Gergen (2007), las narrativas se distinguen entre las progresivas y las regresivas. Las primeras vinculan entre sí acontecimientos, de tal modo que el movimiento a lo largo de la dimensión evaluativa a través del tiempo sea incremental, en tanto que en las segundas el movimiento es decreciente. Al mismo tiempo, el autor considera que en la cultura contemporánea algunas formas de narrativas son la narración trágica 
y la comedia-novela. Describir las formas de narración, junto al drama que se desenvuelve a través de ellas, supone trabajar en la exposición de yoes potenciales, en tanto el narrador debe mantener la inteligibilidad — ser reconocible con un pasado y un futuro- en la cultura, por lo que utiliza las reglas aceptadas en ella para la construcción narrativa.

Bruner (1990) distingue algunos rasgos del pensamiento narrativo y de la narración, los cuales se intrincan por medio del lenguaje y se dificulta su distinción. En primera instancia, los eventos ocurren en un marco temporal, por lo que son diacrónicos; por otra parte, retoma acontecimientos particulares, pero su destino va más allá, por lo que la narrativa es particular. De igual forma, tienen una composición hermenéutica, tanto en su comprensión como en su composición, ya que dependen de la capacidad humana para procesar e interpretar, y se debe prestar atención a los dominios contextuales, las intenciones, las atribuciones y el conocimiento presupuesto, la canonicidad y la ruptura con la legitimidad, pues la narrativa no consiste tanto en fabular nuevos relatos, como en convertir lo que anteriormente era familiar en incierto o problemático, hacer extraño lo ordinario.

En este sentido, la referencialidad contempla que la narrativa no es dependiente de una correspondencia estricta con la realidad, por cuanto la verdad narrativa es juzgada por su verosimilitud y no por su verificabilidad. El género, a su vez, implica maneras de comprender las narrativas y proveer guías interpretativas al público, y también existe la necesidad de tener legitimidad cultural, por lo que se evidencia normatividad. Finalmente, es preciso mencionar la sensibilidad contextual y la negociabilidad, junto con la acumulación narrativa, ya que, en primer lugar, la narrativa se analiza por medio de los presupuestos propios y bajo la luz de las presuposiciones del 
narrador. En definitiva, el producto de una cultura es la acumulación de historias del pasado que posibilitan la continuidad en el presente (Morales, 2005).

\section{Conclusiones}

Dentro de la primera fase epistemológica y conceptual del proyecto Construcciones narrativas sobre construcciones de subjetividad y autorreconocimiento indigena del pueblo nasa. Un pueblo de ancestros, luchas y reivindicaciones, es posible mencionar las siguientes conclusiones:

a) No existe un consenso entre las diferentes instituciones nacionales (ministerios/departamentos) con respecto al número total de pueblos, comunidades y personas que honran la diversidad étnica del país, aumentando así el desconocimiento de la sociedad mayoritaria y de los mismos pueblos indígenas sobre su tasa poblacional y por ende sobre otro tipo de características socioculturales, históricas y económicas.

b) Reconocimiento de la intrincada lucha por la reivindicación de derechos del pueblo nasa-paez como un legítimo otro, que difiere en cosmovisión y prácticas, puntualizando en sus concepciones, temporalidad, armonía y territorio ancestral.

c) El pueblo nasa lleva a cabo una búsqueda profunda por autodefinirse y resignificar nociones dentro de su propia comunidad, mediante la creación de figuras como kiwe thëgu o guardia indígena, y de igual forma, buscando el reconocimiento de la sociedad mayoritaria sobre su existencia y su legitimidad.

d) El llamado pueblo de luchas, reivindicaciones y resistencias ha generado dispositivos para ir en contravía 
de la trasgresión cultural que ha sufrido, en materia de la formalización sobre la propiedad de sus tierras, el goce de territorio-ambiente sano y ecológico, las pérdidas de sus congéneres, la sensación de inseguridad y violación de la libre movilización por el territorio.

e) El segundo pueblo indígena más grande de Colombia requiere que en los escenarios de diálogo/acercamientos actores, como los de participación política (consulta previa) sean visibles sus necesidades particulares.

f) Las narrativas esbozan las particularidades de indigenismo de la nación nasa, aportan a los procesos propios de la comunidad por autodefinirse, al empoderamiento político y a resignificar las maneras de acercarnos a dicho pueblo como cultura occidental.

g) El autorreconocimiento comprende la construcción de subjetividad y el entretejido de intersubjetividades, los procesos de empoderamiento en lucha y el mecanismo de resistencia de los pueblos, pues somos sujetos en proceso.

h) Las narraciones son expresiones políticas en sí mismas, porque delimitan y provienen de la interacción con el otro, funcionan como historias orales que cumplen la función de autoidentificación, autojustificación, autocrítica y solidificación social. Comunidades como las indígenas utilizan la oralidad como recurso narrativo para salvaguardar su historia, cosmogonías e identidad, contrarrestando el riesgo del olvido, y por esta razón sus narrativas tienden a la repetición y se acoplan a un producto social de colonización y vulneración.

i) Develar la subjetividad nasa a través de las narrativas pone en evidencia metarrelatos sobre aproximaciones 
a la reparación integral de este pueblo, contribuyendo desde la disciplina psicológica a la permanencia física y cultural de los pueblos y comunidades indígenas, a través de la divulgación de resultados y la invitación de disciplinas afines a la discusión de estos.

\section{Referencias}

Asamblea Nacional Constituyente (1991). Constitución Política de Colombia. Bogotá D.C.: Presidencia de la Republica de Colombia.

Bravo, O. (2011). Trauma, memoria, justicia y reparación. Revista Electrónica de Psicología Social Poiésis, (22).

Bruner,J. (1990). Actos de significado. Más allá de la revolución cognitiva. Madrid: Alianza Editorial.

Congreso de la República de Colombia (1890). Ley 89 de 1890 (noviembre 16) Por la cual se determina la manera como deben ser gobernados los salvajes que se reduzcan a la vida civilizada. Bogotá, D.C.: Presidencia de Colombia.

Congreso de la República de Colombia (1991). Ley 21 de 1991 (marzo 4) por medio de la cual se aprueba el convenio número 169 sobre pueblos indígenas y tribales en países independientes, adoptado por la $76^{\text {a. }}$ reunión de la Conferencia General de la oiт, Ginebra 1989. Bogotá,D.C.: Presidencia de Colombia.

Congreso de la República de Colombia (1995). Decreto 2164 de 1995 (diciembre 7) Por el cual se reglamenta parcialmente el Capítulo xiv de la Ley 160 de 1994 en lo relacionado con la dotación y titulación de tierras a las comunidades indígenas para la constitución, reestructuración, ampliación y saneamiento de los Resguardos Indígenas en el territorio nacional. Bogotá: D. C.: Presidencia de Colombia. 
Congreso de la República de Colombia (1995). Ley 160 de 1994 (agosto 3) Por la cual se crea el Sistema Nacional de Reforma Agraria y Desarrollo Rural Campesino, se establece un subsidio para la adquisición de tierras, se reforma el Instituto Colombiano de la Reforma Agraria y se dictan otras disposiciones. Bogotá, D.C.: Presidencia de Colombia.

Congreso de la República de Colombia (2011). Ley 1448 de Victimas y restitución de tierras. Bogotá, D.C. Diario oficial 48096 de junio 10 de 2011. Presidencia de Colombia.

Corte Constitucional de la República de Colombia (2009). Auto 004. Protección de derechos fundamentales de personas e indígenas desplazados por el conflicto armado en el marco de superación del estado de cosas inconstitucional. Bogotá, D. C.: Presidencia de Colombia.

Corte Constitucional de la República de Colombia (2010). Auto 382. Seguimiento sentencia T-025/04 y auto A004/09. Bogotá, D. C.: Presidencia de Colombia.

Corte Constitucional de la República de Colombia (2011). Decreto-ley 4633 (diciembre 9) Por medio del cual se dictan medidas de asistencia, atención, reparación integral y de restitución de derechos territoriales a las víctimas pertenecientes a los pueblos y comunidades indígenas. Bogotá, D. C.: Presidencia de Colombia.

Díaz Gómez, A. y González Rey, F. (2005). Subjetividad: una perspectiva histórico-cultural: Conversación con el psicólogo cubano Fernando González Rey. Universitas Psychologica, 4 (3), 373-383. Recuperado el $1^{\circ}$ de diciembre del 2014, de http:// www.scielo.org.co/scielo.php?script=sci_arttext\&pid=S165792672005000300011\&lng=en\&tlng=es

Equipo Nacional de Salvaguardia (s.f.) Plan de salvaguardia de la nación Nasa. Ministerio del Interior. Recuperado de http:// 
www.mininterior.gov.co/sites/default/files/p.s_nasa_version_preliminar.pdf

Gergen, K. (2007) Construccionismo social. Bogotá: Universidad de los Andes-ceso. Recuperado de http://www.taosinstitute. net/Websites/taos/images/PublicationsFreeBooks/Gergen_construccionismo_social.pdf

Guilis, G. (2005). El concepto de reparación simbólica. Memorias Seminario Internacional de Integración de Abordajes y Acciones Psicosociales en la Asistencia Jurídica a Víctimas. Bogotá: Corporación Avre. Recuperado de http://www. corporacionavre.org/files/pdf/SeminarioInternacional/capitulo1.pdf

Mendoza, J. (2004). Las formas del recuerdo. La memoria narrativa. Athenea Digital, (6), 1-16. Recuperado de http://ddd. uab.es/pub/athdig/15788946n6a11.pdf

Morales, J. (2005). Teoría narrativa de la psicología social en el modo de ser literario. Tesina de la Universidad Autónoma de Barcelona. Recuperado de http://www.tdx.cat/bitstream/ handle/10803/5442/jmg1de1.pdf?sequence=1

Observatorio del Programa Presidencial de Derechos Humanos y Derecho Internacional Humanitario (2010). Diagnóstico de la situación del pueblo indígena nasa o paez. Recuperado de: http://www.derechoshumanos.gov.co/Observatorio/Documents/2010/DiagnosticoIndigenas/Diagnostico_NASAP\%C3\%81EZ.pdf

Página Oficial Observatorio por la Autonomía y los Derechos de los Pueblos Indígenas en Colombia (ADPI) (s.f.). Pueblo nasa. Recuperado de http://observatorioadpi.org/nasa

Página oficial onic (s.f.). Pueblos indígenas. ¿̇Cuáles son, cuantos y donde se ubican los pueblos indígenas de Colombia? Recuperado de http://cms.onic.org.co/pueblos-indigenas/ 
Página oficial Universidad del Rosario (s.f.) Legislación colombiana para comunidades étnicas. Recuperado de http://www. urosario.edu.co/jurisprudencia/catedra-viva-intercultural/ ur/Legislacion-colombiana-para-comunidades-etnicas/ y http://190.25.231.237:81/gruposEtnicos/doc/NormatividadResguardosIndigenas.pdf

Rojas, L. (2013). Narrativa historica, narrativas cotidianas: la memoria como campo de lucha en el caso de la masacre de Trujillo (tesis). Fundación Universitaria Los Libertadores, Bogotá. 